\title{
Infrared Photodissociation of Non-Covalent Adducts of Electrosprayed Nucleotide Ions
}

\author{
Daniel P. Little* and Fred W. McLafferty* \\ Baker Chemistry Laboratory, Cornell University, Ithaca, New York, USA
}

Efficient dissociation of gaseous non-covalent adducts of multiply charged DNA anions can be effected by infrared irradiation to yield minimal dissociation of the DNA molecular ions-far less dissociation than by collisional activation. Examples include removal of adducted impurities from 100-mer DNA anions and removal of all 14 adducted molecules of 1,4-diaminobutane from $\mathrm{M}^{15-}$ to $\mathrm{M}^{17-}$ of a 50-mer DNA. (J Am Soc Mass Spectrom 1996, 7, 209-210)

$\mathrm{E}$ lectrospray ionization (ESI) [1] is an unusually gentle ionization method, that makes possible the ionization of an adduct of multiple molecules not joined by covalent bonds to produce an ionized species whose mass corresponds to the sum of the masses of the adduct molecules. To exploit this phenomenon, many studies have compared the non-covalent binding tendency of such gaseous ions with the tendency of those found in solution [2]. However, non-covalent adducts from unknown impurities can seriously complicate the ESI spectrum of a molecule used for study of its structure alone; adducts produce ions whose higher masses have no clear relationship to the molecule's structure. Cationic adduction (e.g., $\mathrm{Na}$ ) is an additional problem, especially for ESI negative ions, but a variety of methods to minimize these adducts have been found [3]. However, both this and non-covalent adduction become more acute with increasing molecular size, as larger molecules in general are more difficult to purify and have more molecular sites for adduction. As a solution to the non-covalent problem, the addition of energy to the gaseous adduct ions should preferentially cleave the weaker non-covalent (versus covalent) bonds. For porcine albumin (67 $\mathrm{kDa}$ - - a "sticky" protein-infrared multiphoton dissociation (IRMPD) [4] was found to be far more effective than collisional activation to detach the non-covalent adduct impurities (which added $>1000 \mathrm{Da}$ to the molecular mass) versus dissociation of the molecular ion itself [5]. However, the problem of unwanted noncovalent adducts of negative ESI ions has not been

Address communications to Professor F. W. McLafferty, Baker Chemistry Laboratory, Cornell University, Ithaca, NY 14853-1301.

*Current address: SEQUENOM Instruments GbmH, Hallerstrasse 74, 20146 Hamburg, Germany. addressed; severely adducted molecular ions of a 100mer DNA molecule were reported recently [3e]. This IRMPD technique is extended here to ESI of another 100-mer DNA molecule. Sequence information derived from the resulting Fourier transform mass spectra is described separately (Little, D. P.; Aaserud, D. J.; Valaskovic, G. A.; McLafferty, F. W., to appear; hereafter referred to as [LAVM]).

The electrospray ionization-Fourier transform mass spectrometry (ESI-FTMS) system described previously ([4-6] and [LAVM]) was used with infusion of a solution (4 $\mu \mathrm{m}$ in $75 \% \quad \mathrm{CH}_{3} \mathrm{CN}, 0.01 \%$ piperidine; 1 $\mu \mathrm{L} / \mathrm{min}$ ) of an $\mathrm{A}_{22} \mathrm{~T}_{32} \mathrm{C}_{22} \mathrm{G}_{24}$ 100-mer [LAVM] from the Cornell Peptide/DNA Synthesis Facility. Despite two high-performance liquid chromatography desalts to remove cationic adducts from the freshly synthesized 100-mer [3e], ESI only yields (Figure 1a) a broad hump from $m / z \sim 700$ to 1100 , with no resolved isotopic or charge state peaks, which indicates that the molecular ions are adducted heavily. "Boiling off" non-covalent adducts with collisional activation under a variety of conditions (not shown) reduces the adducts, but also causes molecular ion dissociation, as found for large proteins [5]. However, IR irridiation of the 100-mer ions reduces non-covalent adducts to a minor role and yields isotopic resolution (Figure $1 \mathrm{~b}$ and inset) without appreciable covalent bond dissociation. Combination of the data of all charge states by deconvolution [7] (Figure 1c) shows the extensive cationic adduction is still present. Despite this, the experimental mass of the nonadducted ions $(30,824.0 \mathrm{Da})$ is in good agreement with the calculated $M_{\mathrm{r}}$ value $(30,825.1 \mathrm{Da})$. By using ESI-FTMS for sequence verification, this $M_{\mathrm{r}}$ value easily would rule out, for example, methylation (+14 Da) or a base switch (e.g., $\mathrm{T} \rightarrow$ A, $\Delta m=9 \mathrm{Da}$ ). However, even after non-covalent adduct reduction, measurement of $M_{\mathrm{r}}$ of these cation- 


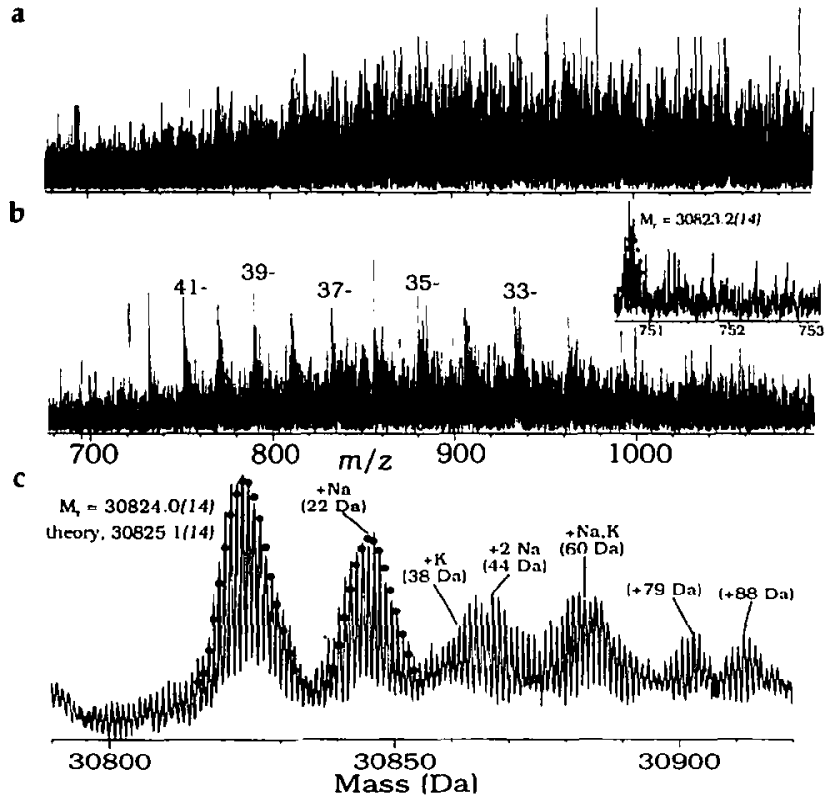

Figure 1. Negative ion ESI-FTMS spectra of a 100-mer DNA (a) before IR irradiation and (b) after 200-ms IR (inset: $M^{+1}$ region). (c) Deconvolution of spectrum (b).

ated ions by using conventional instrumental resolving power $\left(\leq 10^{3}\right)$ would give a centroid value $\sim 30 \mathrm{Da}$ high; this would be completely misleading for identification of such minor mutations.

Testing this with known impurities, addition of $0.05 \%$ 1,4-diaminobutane $\left(\mathrm{DAB} ; M_{\mathrm{r}}=88.10 \mathrm{Da}\right)$ to a solution of a 50-mer $\mathrm{A}_{10} \mathrm{~T}_{10} \mathrm{C}_{17} \mathrm{G}_{13}$ DNA [LAVM], results in an ESI-FTMS spectrum with peaks separated by $88.1 \mathrm{Da}$ (Figure 2a). An increase in the NS potential difference only partially removes these adducts before creation of fragment ions (spectrum not shown). However, IRMPD does remove DAB effectively (Figure $2 \mathrm{~b}-\mathrm{d}$ ); the $17-\mathrm{ms}$ irradiation necessary for nearly complete removal shows only a minor amount of base A loss, the lowest energy dissociation process [LAVM]. The sensitivity is also increased manyfold by this simplification of the spectrum. Note that the degree of adduction increases with decreasing negative charge, as found for cationic adducts of multiply charged nucleotide anions [3c].

Routine use of IRMPD to attempt to simplify ESI mass spectra without causing dissociation of either molecular anions or cations should be especially valuable for unknown large molecules, which include DNA, and for instruments of limited resolving power.

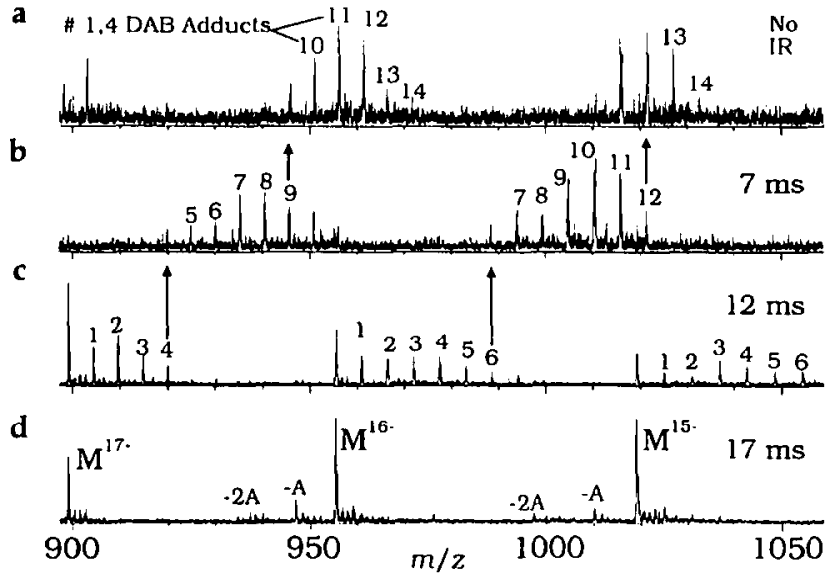

Figure 2. Partial ESI-FTMS spectrum of a 50-mer DAN plus $0.05 \%$ (by weight) diaminobutane, after (a) $0,(b), 7$, (c) 12 , and (d) $17 \mathrm{~ms}$ of IR irradiation.

\section{Acknowledgments}

The authors thank D. J. Aaserud, E. K. Fridriksson, N. L. Kelleher, J. P. Speir, G. A. Valaskovic, and C. Van Pelt for experimental assistance, T. W. Thannhauser for DNA synthesis and purification, and the National Institutes of Health for financial support (Grant GM16609).

\section{References}

1. Clegg, G. A.; Dole, M. Biopolmers 1971, 10, 821-826; Fenn, J. B.; Mann, M.; Meng, C. K.; Wong, S. F.; Whitehouse, C. M. Science 1989, 240, 64-71.

2. Ganem, B.; Li, Y.-T.; Henion, J. D. J. Am. Chem. Soc. 1991, 113, 6294-6296; Cheng, X.; Chen, R.; Bruce, J. E.; Schwartz, B. L.; Anderson, G. A.; Hofstadler, S. A.; Gale, D. C.; Smith, R. D.; Gao, J.; Sigal, G. B.; Manmen, M.; Whitesides, G. M. I. Am. Chem. Soc. 1995, 117, 8859-8860.

3. (a) Stults, J. T.; Marsters, J. C. Rapid Commun. Mass. Spectrom. 1991, 5, 359-363; (b) Potier, N.; Van Dorsselaer, A.; Cordier, Y.; Roch, O.; Bischoff, R. Nicleic Acits Res. 1994, 22, 3895-3903; (c) Little, D. P.; Chorush, R. A.; Speir, J. P.; Senko, M. W.; Kelleher, N. L.; McLafferty, F. W. J. Am. Chem. Soc. 1994, 116, 4893-4897; (d) Greig. M.; Griffey, R. H. Rapid Commun. Mass Spectrom. 1995, 9, 97-102; (e) Little, D. P.; Thannhauser, T. W.; McLafferty, F. W. Proc. Notl. Acull. Sci. USA 1995, 92, 2318-2322.

4. Little, D. P.; Speir, J. P.; Senko, M. W.; O'Connor, P. B., McLafferty, F. W. Amal. Chem. 1994, 66, 2809-2815.

5. Speir, J. P.; Senko, M. W.; Little, D. P.; Loo, J. A.; McLafferty, F. W. I. Mass Spectrom. 1995, 30, 39-42.

6. Beu, S. C.; Senko, M. W.; Quinn, J. P.; Wampler, F. M., III; Mcl.afferty, F. W. I. Am. Soc: Mass Spertrom. 1993, 4, 557-565.

7. Mann, M.; Meng, C. K.; Fenn, J. B. Anal. Clim. 1989, 61, 1702-1708; Reinhold, B. B.; Reinhold, V. N. J. Am. Soc. Mass Spectrom. 1992, 3, 207-215. 